\title{
Population Data Management Information System Of Population And Civil Registration Department
}

\section{Sistem Informasi Pengelolaan Data Kependudukan Dinas Kependudukan Dan Pencatatan Sipil}

\author{
$1^{\text {st }}$ Nurul Latifah ${ }^{1}, 2^{\text {nd }}$ Arizona Firdonsyah ${ }^{2}$ \\ \{latifahn975@gmail.com1, arizona@unisayogya.ac.id² \} \\ Program Studi Teknologi Informasi, Fakultas Sains dan Teknologi, Universitas 'Aisyiyah Yogyakarta1,2
}

\begin{abstract}
Population data is the main supporting component needed in data processing in the population office, population data must be recorded and managed so that it becomes a complete, structured and clearly organized database. The data that has been successfully obtained is used for monitoring the population in the environment. The Sleman Regency Population and Civil Registration Office has been using various systems based on each sector, but with this there are still some obstacles faced in the process of collecting population data in Sleman Regency. The purpose of this research is to describe the implementation of the Population Administration Information System in the Management of Identity Cards (KTP) at the Department of Population and Civil Registration in Sleman Regency. Data collection was carried out by the stages of field studies, literature studies, data collection by means of interviews to observation, data processing, then analysis and conclusions. The data were analyzed qualitatively and quantitatively. This research is also used as material for an overview of the flow of the existing system in the Office of Population and Civil Registration (DUKCAPIL) of Sleman Regency, regarding the feasibility and efficiency of database management from systems related to population data in Sleman Regency. The results of this study are in the form of a data entry flow design to an information system that can be used as a reference or guide and produce physical forms in the form of KIA, KK and KTP in the Department of Population and Civil Registration of Sleman Regency.
\end{abstract}

Keywords - data; information system; sleman regency population and civil registration office

Abstrak. Data kependudukan merupakan komponen penunjang utama yang dibutuhkan dalam pengolahan data di kantor kependudukan, data penduduk harus direkam dan di kelola agar menjadi sebuah database yang lengkap, terstruktur dan organisir dengan jelas. Data yang berhasil didapatkan guna proses monitoring penduduk yang berada pada lingkungan tersebut. Kantor Kependudukan dan Pencatatan Sipil Kabupaten Sleman selama ini telah menggunakan berbagai sistem berdasarkan masing-masing bidang, namun dengan ini masih terdapat beberapa kendala yang dihadapi dalam proses pengumpulan data kependudukan di Kabupaten Sleman. Tujuan penelitian untuk mendeskripsikan Implementasi Sistem Informasi Administrasi Kependudukan dalam Pelayanan Pengurusan Kartu Tanda Penduduk (KTP) pada Dinas Kependudukan dan Pecatatatan Sipil Kabupaten Sleman. Pengumpulan data dilakukan dengan tahapan studi lapangan, studi literatur, pengumpulan data dengan cara wawancara hingga observasi, pengolahan data, lalu analisa dan kesimpulan. Teknik analisis data dilakukan secara kualitatif dan secara kuantitatif. Penelitian ini juga sebagai bahan tinjauan mengenai alur sistem yang ada di Kantor Kependudukan dan Pencatatan Sipil (DUKCAPIL) Kabupaten Sleman, mengenai kelayakan dan efesiensi pengelolaan database dari sistem terkait data penduduk di Kabupaten Sleman. Hasil penelitian ini berupa rancangan alur entry data ke sistem informasi yang dapat digunakan sebagai bahan acuan atau panduan dan menghasilkan bentuk fisik berupa KIA, KK, dan KTP di Dinas Kependudukan dan Pencatatan Sipil Kabupaten Sleman.

Kata Kunci - data; sistem informasi; kantor kependudukan dan pencatatan sipil kabupaten sleman

\section{Pendahuluan}

Kabupaten Sleman ditinjau dari titik Geografis terletak antara $110^{\circ} 33^{\prime} 00^{\prime \prime}$ dan $110^{\circ} 13^{\prime} 00^{\prime \prime}$ Bujur Timur, $7^{\circ} 34^{\prime}$ $51^{\prime \prime}$ dan $7^{\circ} 47^{\prime} 30^{\prime \prime}$ Lintang Selatan. Letak wilayah berada di sebelah utara berbatasan dengan Kabupaten Boyolali, Propinsi Jawa Tengah, sebelah timur berbatasan dengan Kabupaten Klaten, Propinsi Jawa Tengah, sebelah barat berbatasan dengan Propinsi DIY, Kabupaten Kulon Progo dan Kabupaten Magelang, Propinsi Jawa Tengah dan sebelah selatan berbatasan dengan Kabupaten Bantul, Kota Yogyakarta dan Kabupaten Gunung Kidul, Propinsi D.I.Yogyakarta. Administratif Kabupaten Sleman terdiri dari 17 kecamatan dengan 86 desa dan 1212 dusun[1]. Wilayah Kabupaten Sleman berbatasan dengan semua kabupaten yang ada di Provinsi Daerah Istimewa Yogyakarta dan juga Propinsi Jawa Tengah.

Kantor DUKCAPIL Sleman merupakan salah satu kantor lembaga pemerintahan yang bertujuan untuk menyelenggarakan dan penataan struktur data pencatatan kependudukan. Data yang terstruktur tentunya memerlukan 
sebuah sistem yang nantinya menghasilkan sebuah database. DUKCAPIL Kabupaten Sleman telah memiliki beberapa sistem yang digunakan yang digunakan sesuai dengan bagian masing-masing, contoh: pada bagian pendaftaran kependudukan menggunakan SIAK (Sistem Informasi Administrasi Kependudukan), bagian arsiparis menggunakan SIMARDA (Sistem Manajemen Arsip Daerah), bagian sekretaris menggunakan Sistem Kesekertaritan, bagian Keuangan menggunakan SIADINDA (Sistem Administrasi Daerah) dan masih terdapat beberapa sistem lainnya, baik untuk internal maupun untuk pelayanan masyarakat umum.

Pelayanan publik menurut Thaha merupakan suatu kegiatan yang harus mendahulukan kepentingan umum, mempermudah urusan publik, mempersingkat waktu pelayanan dan memberikan kepuasan pada publik[14]. Pemenuhan hak masyarakat yang merupakan tujuan dari fungsi pelayanan publik harus terus ditingkatkan baik dari sisi kualitas, maupun kuantitas. Sisi kualitas dapat dilakukan dengan mengurangi kesalahan pelayanan, mempercepat pelayanan, dan kemudahan pelayanan[2]. Sedangkan dari sisi kuantitas dapat dilakukan dengan memperbanyak jumlah masyrakat yang dapat di layani dan menambah waktu pelayanan. Salah satu bentuk penerapan tenologi informasi dalam e-government ini adalah penggunaan Sistem Informasi Administrasi Kependudukan (SIAK) dalam pengelolaan data penduduk untuk menjalankan pengintegrasian data penduduk.

Sistem Kependudukan memiliki peran penting dalam kegiatan kantor. Kantor atau Pemerintahan memerlukan sebuah hingga beberapa sistem yang digunakan untuk melakukan pencatatan, pengelolaan dan penginformasian mengenai kependudukan daerah[3].

BAGAN SUSUNAN ORGANISASI DINAS KEPENDUDUKAN DAN PENCATATAN SIPIL

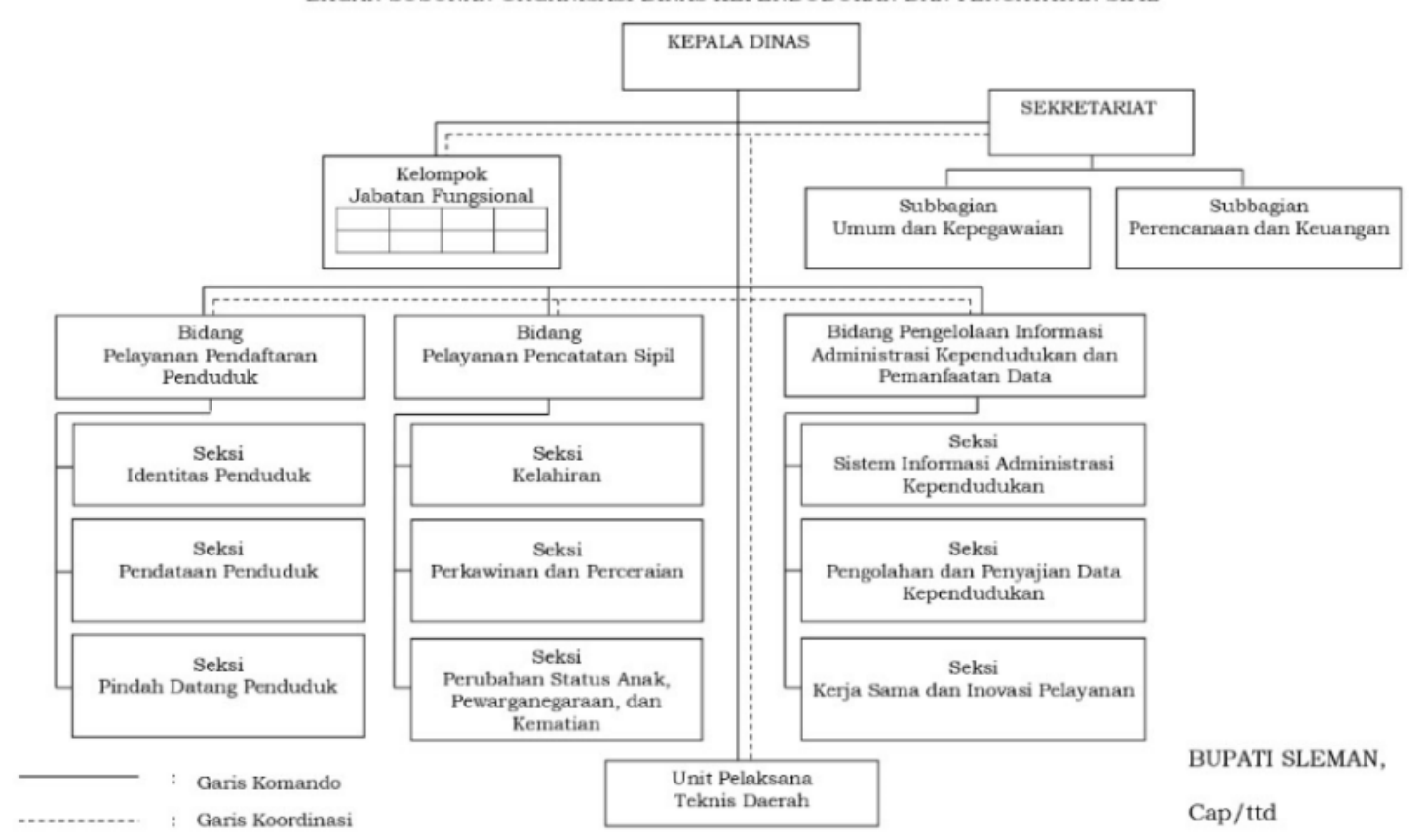

SRI PURNOMO

\section{Gambar 1 Struktur Organisasi Kantor DUKCAPIL Sleman}

Kantor DUKCAPIL Kabupaten Sleman dipimpin oleh Kepala Dinas yang memiliki anggota bagian sekretaris dan kelompok jabatan fungsional, pada sekretariat memiliki subbagian umum \& kepegawaan dan subbagian perencanaan \& keuangan. Kepala Dinas juga bertanggung jawab langsung pada bidang-bidang yang ada, Bidang Pelayanan Pendaftaran Penduduk yang terdiri dari 3 seksi (Identitas Penduduk, Pendataan Penduduk, dan Pindah Datang Penduduk), Bidang Pelayanaan Pencatatan Sipil terdiri dari 3 seksi diantaranya perkawinan, kelahiran, perubahan status anak, perceraian, pewarganegaraan dan kematian, Bidang Pengelolaan Informasi Administrasi Kependudukan dan Pemanfaatan Data terdiri dari 3 seksi diantaranya administrasi kependudukan, pengolahan dan penyajian data kependudukan, kerja sama dan inovasi pelayanan. Seluruh bidang yang telah disebutkan Unit Pelaksana Teknis Daerah juga berkoordinasi kepada Kepala Dinas langsung.

Database merupakan kumpulan data yang dikelola berdasarkan ketentuan tertentu yang saling terikat dan berhubungan sehingga dapat mudah dikelola. Data yang tertata dengan rapi dan tertata dari pengguna dapat memperoleh kemudahan dalam mencari informasi, menyimpan informasi dan membuang informasi[1]. Basis data juga bisa diartikan sekumpulan data dan informasi yang tersimpan dan tersusun rapi pada ruang penyimpanan komputer secara sistematik sehingga mudah saat diakses oleh program komputer guna mencari keberadaan suatu data agar mudah ditemukan dan dikelola sesuai dengan kebutuhan. 
Database terdiri dari 5 jenis, yaitu:

1) Operational Database atau biasa disebut dengan database OLTP (On Line Transaction Processing), berguna untuk mengelola data yang dinamis secara langsung atau real-time, produk: JSON, XML.

2) Database Warehouse, sistem basis data yang biasa digunakan untuk pelaporan dan analisis data. Sistem ini dianggap sebagai komponen inti dari business intelligence, produk: Microsoft SQL Server[4].

3) Distributed Database adalah basis data yang perangkat penyimpanannya tidak terpasang pada perangkat komputer yang sama, produk: Microsoft Access.

4) Relational Database atau basis data relasional, basis data yang mengorganisir berdasarkan model hubungan data[2]. Perangkat lunak yang menggunakan sistem ini untuk mengatur dan memelihara basis data melalui hubungan setiap data, produk: MySQL, PostgreSQL, Maria DB, MongoDB, Oracle Database, SAP Hana, IBM Db2, MemSQL, Interbase, Firebird.

5) End User Database, basis data yang berhubungan langsung dengan user ataubisa disebut dengan client server, produk: SQLite [3].

Database yang digunakan untuk beberapa sistem yang digunakan untuk melakukan pendataan, pecatatan dan pengelolaan data kependudukan adalah MySQL. MySQL adalah sebuah DBMS (Database Management System) dengan menggunakan perintah SQL(Structured Query Language) untuk pengoperasiannya, basis data ini banyak digunakan untuk pembuatan aplikasi berbasis website. Database ini memliki 2 lisensi diantaranya Free Software yaitu dimana perangkat lunak dapat diakses oleh siapa saja dan Shareware dimana perangkat lunak berpemilik memiliki batasan untuk penggunaan dan pengoperasiannya[5].

\section{METODE}

Metode yang diterapkan pada saat melakukan praktek kerja di Kantor Kependudukan dan Pencatatan Sipil Kabupaten Sleman yakni menggunakan data primer dan sekunder.

Metode Penelitian yang dilakukan memiliki 6 tahapan:

1. Studi Lapangan

Lokasi penelitian sangatlah penting dikarenakan adanya beberapa pertimbangan akan berpengaruh terhadap sample dan hasil dari penelitian berdasarkan kasus yang diambil. Pemilihan lokasi dapat diambil berdasarkan kriteria yang dimaksudkan untuk upaya penelitian lebih tepat sasaran sehingga mampu menggambarkan apapun untuk capaian penelitian ini. Upaya yang dapat dilakukan untuk memperoleh data dengan melakukan pengamatan secara langsung terhadap materi dan objek yang akan diteliti untuk mendapatkan informasi mengenai permasalahan[6].

2. Studi Literatur

Tahap ini merupakan suatu cara yang digunakan untuk mengumpulkan data berdasarkan sumber berhubungan dengan topik yang diangkat.

3. Pengumpulan Data

Penelitian ini memiliki 2 jenis data guna untuk mengumpulkan data yaitu data primer dan data sekunder. Perolehan data primer dari hasil wawancara langsung dengan pihak terkait yakni kepala bidang hingga pegawai, pengamatan di lapangan secara langsung terhadap kegiatan yang berkaitan dengan proses sistem[7]. Alur proses bisnis serta output yang dihasilkan juga mempelajari secara langsung dengan cara melakukan kegiatan yang dilakukan saat praktek kerja. Data sekunder diperoleh secara tidak langsung yaitu melalui jurnal, buku panduan, studi pustaka, buku-buku, maupun literatur lainnya yang berkaitan dengan kegiatan yang dilakukan, guna untuk menunjang kegiatan praktek kerja hingga penyelesian laporan praktek kerja.

4. Pengolahan Data

Data yang telah berhasil diperoleh dan dikumpulkan, selanjutnya dilakukan analisis data yang bertujuan untuk memberi arti dan makna pada data serta berguna untuk memecahkan masalah dalam penelitian yang sudah dirumuskan.

5. Analisa

Identifikasi data analisa yang digunakan diantaranya analisis data statistika deskriptif, statistika inferensial dan pengujian persyaratan analisis. Analisis data statistika deskriptif dapat disajikan dalam bentuk gambar alur serta diagram[8].

6. Kesimpulan

Hasil yang telah didapatkan harus sesuai dengan topik yang dibahas, dengan ini mampu menghasilkan data yang sesuai dengan apa yang terjadi dilapangan sehingga dapat menjadi pacuan dan sumber referensi. 


\section{Hasil dan Pembahasan}

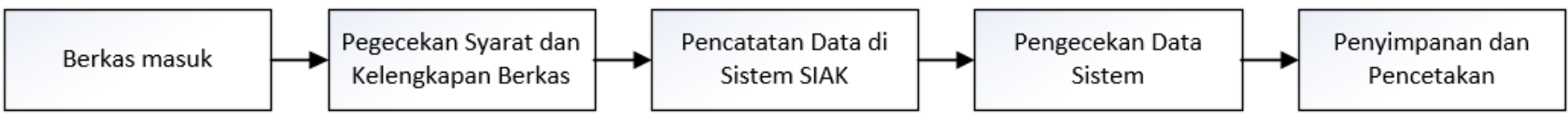

\section{Gambar 2 Alur Pencatatan Data Sistem}

Langkah pertama yang harus dilakukan untuk melakukan pencatatan data atau pencatatan penduduk, alurnya seperti pada gambar 2 pertama berkas masuk melalui loket yang ada di depan untuk melayani masyarakat setelah itu berkas akan dicek dan diteliti mengenai kelengkapan persayatan, lalu berkas akan diserahkan bidang atau bagian pencatatan sipil disini dana akan dicatat dan diolah sebelum data masuk ke langkah selanjutnya[9]. Bagian pencatatan akan melakukan pengecekan 2 kali yakni melalui sistem dan pencocokan secara manual, pertama akan dicocokan dengan sistem yang sudah ada berikutnya selanjutnya tahap 2 untuk mengecek dengan mencocokan data atau informasi di sistem dengan berkas asli yang diserahkan di loket administrasi[9].

Implementasi Sistem Informasi Administrasi Kependudukan (SIAK) dalam Pelayanan Pengurusan Kartu Tanda Penduduk (KTP) pada Dinas Kependudukan dan Catatan Sipil Kabupaten Sleman dibahas berdasarkan kerangka pikiir penelitian yang dibangun atau ditetapkan dalam penelitian. Implementasi kebijakan merupakan tindakan yang dilaksanakan atau tidak dilaksanakan oleh instansi atau pejabat berdasarkan pertimbangan aturan-aturan yang dikelurkan oleh pemerintah terkait demi tercapainya tujuan dari organisasi tersebut. Keberhasilan hingga tercapai atau tidak tercapainya tujuan organisasi dipengaruhi oleh faktor-faktor tersebut dalam pelaksanaan implementasi kebijakan.

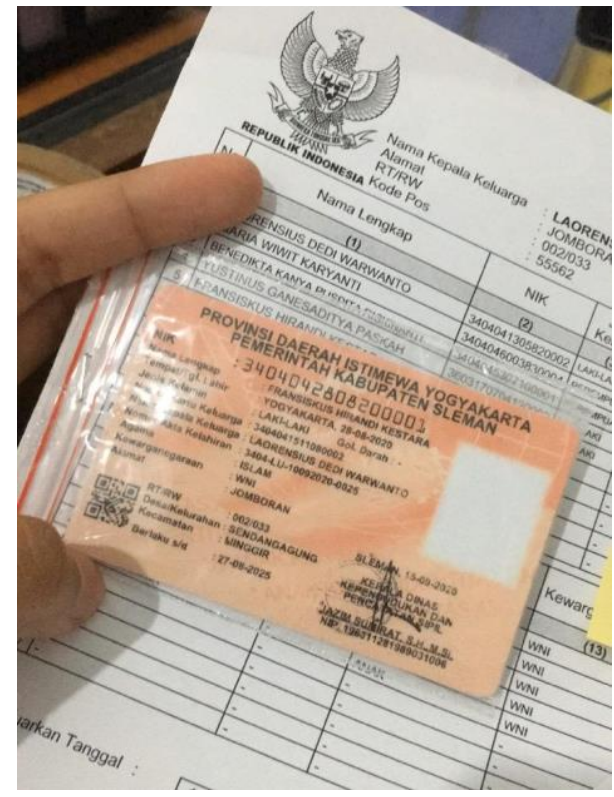

\section{Gambar 3 Kartu Identitas Anak dan KK}

Gambar 3 merupakan Kartu Identitas Anak (KIA) beserta KK yang telah berhasil dicetak berdasarkan data yang ada pada Sistem Informasi Administrasi Kependudukan (SIAK). 
Procedia of Engineering and Life Science Vol. 1. No. 2 Juni 2021

Seminar Nasional \& Call Paper Fakultas Sains dan Teknologi (SENASAINS 2nd)

Universitas Muhammadiyah Sidoarjo

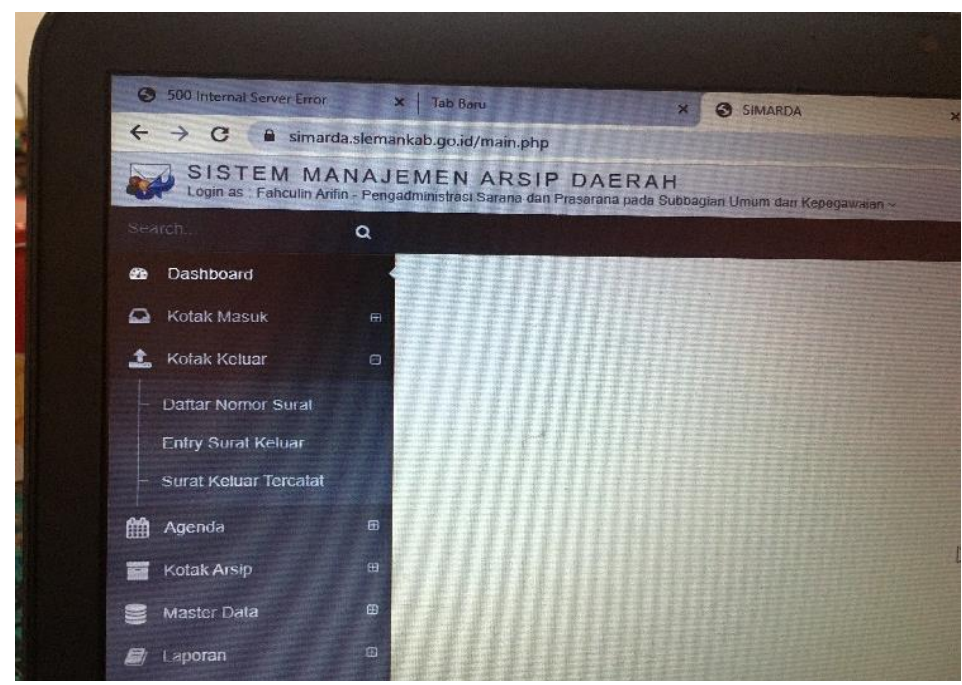

Gambar 4 Tampilan Dashboard SIMARDA

Gambar 4 merupakan tampilan awal dari Sistem Manajemen Arsip Daerah (SIMARDA). Tampilan tersebut menampilkan berbagai bagian pendataan diantaranya Kotak Masuk dan keluar terkait data surat masuk dan keluar, agenda kegiatan arsip, kotak arsip hingga laporan.

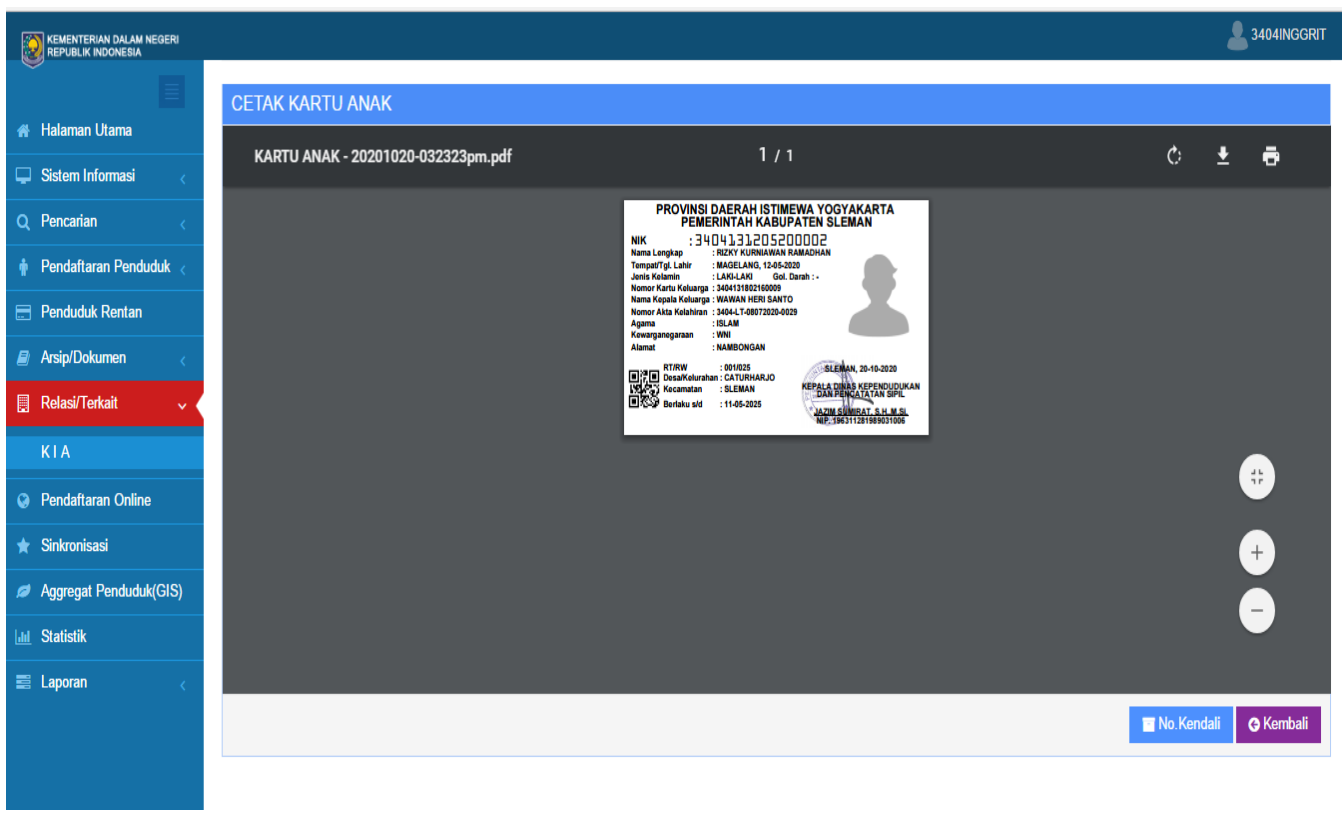

Gambar 5 Tampilan Pencetakan KIA

Gambar 5 merupakan tampilan untuk melakukan proses pencetakan Kartu Identitas Anak (KIA), sebelumnya data diperoleh dari data anak yang telah dimasukkan pada Sistem Informasi Administrasi Kependudukan (SIAK).

\section{A. Sarana dan Prasarana}

Menurut Kamus Besar Bahasa Indonesia sarana merupakan segala sesuatu yang berguna sebagai tools dalam mencapai maksud dan tujuan. Sedangkan prasarana menurut KBBI segala sesuatu yang merupakan penunjang untuk terselenggaranya suatu proses baik usaha, pembangunan, dan proyek[4]. Upaya untuk mendukung berjalannya Sistem Informasi Administrasi Kependudukan tentu diperlukan sarana dan prasarana yang memadai agar lebih efektif dalam menghasilkan produk-produk SIAK. Kantor Dinas Kependudukan dan Pencatatan Sipil Kabupaten Sleman memiliki berbagai sarana dan prasana untuk menunjang keberlangsungan proses pelayanan yang diberikan[10]. Berdasarkan hasil penelitian yang telah dilakukan dapat disimpulkan bahwa dari segi sarana dan prasarana yang digunakan untuk melakukan proses pendataan data penduduk di kabupaten Sleman sudah 
memadahi bahkan bisa diikatakan lengkap sehingga selama ini tidak ada kendala dan permasalahan terkait sarana dan prasarana, baik untuk pendataan dan pengelolaan data penduduk.

\section{B. Alur Kerja}

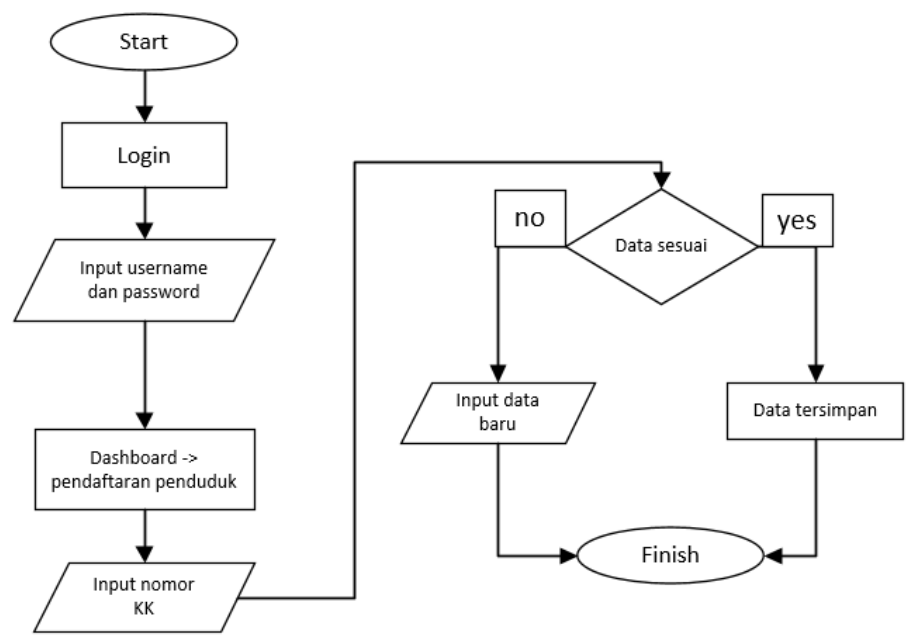

\section{Gambar 6 Diagram Alir Entry Data Baru}

Gambar 6 menerangkan mengenai diagram alur entry data baru yang dicetak sebagai KK atau KIA. Pemasukan data ini dilakukan di Sistem Informasi Administrasi Kependudukan (SIAK), langkah pertama melalukan login dengan username dan password lajut akan masuk ke halaman dashboard masuk ke pendaftaran penduduk, klik input nomor KK untuk mengecek apakah data yang akan dimasukkan sudah ada dan sudah sesuai atau belum. Jika sudah sesuai klik pada status simpan untuk melakukan penyimpanan sistem bahwa data sudah benar dan sesuai dan jika belum sesuai klik entry data baru lalu masukkan elemen-elemen data yang wajib dan tidak wajib untuk diisi selanjutnya simpan data agar data diperbarui.

Kartu Identitas Anak dan KK dibuat pada awalnya menerima dokumen dari bidang pelayanan, kemudian dokumen tersebut diseleksi untuk kelengkapan data oleh bidang pencatatan penduduk. Data yang sudah lengkap dan valid maka diakukan entry data menggunakan Sistem Informasi Administrasi Kependudukan. Data terkait Penduduk, Kepala Keluarga, Status Hubungan Keluarga, Kartu Keluarga, Agama, Pekerjaan, Pendidikan, Golongan Darah, Status Nikah, Kepemilikan Akta, Kelainan Fisik dan Mental, Data Kelahiran dan data Kematian.

Dokumen yang telah selesai digunakan untuk entry data selanjutnya dokumen diberikan kepada bagian pencetakan KK, ini bertujuan untuk dilakukan pengecekan ulang data mengenai kecocokan data yang masuk ke sistem dengan dokumen yang masuk[11]. KIA juga dilakukan pengecekan kembali sebelum dicetak bedanya dengan KK, KIA dapat dicetak oleh hampir semua karyawan yang ada di bidang pencatatan penduduk sedangkan KK hanya karyawan tertentu yang memiliki wewenang untuk melakukan pencetakan.

Dokumen yang sudah digunakan akan dikumpulkan 1 bulan sebelum diserahkan ke bidang arsip. Bidang arsip menerima dokumen-dokumen dari berbagai bidang sehingga banyak sekali dokumen yang perlu utuk disimpan dan harus dimusnahkan. Sejatinya data penduduk bersifat rahasia, sehingga diperlukan kehati-hatian untuk mengolah dokumen-dokumen yang ada.

\section{Analisis}

Dinas Kependudukan dan Pencatatan Sipil di Kabupaten Sleman ini telah menggunakan komputerisasi data dengan ini data dapat tersalur dengan baik antar pegawainya, sehingga mudah untuk dilakukan pengecekan dan pengelolaan data baik untuk kebutuhan modifikasi ataupun pengecekan saja. Data yang dikelola pada sistem informasi di berbagai bidang sudah digunakan dengan baik dan terintegrasi, tidak hanya membutuhkan hardskill saja akan tetapi juga membutuhkan softskill untuk menjalankan kegiatan atau pekerjaannya[12].

Sistem Informasi Administrasi Kependudukan (SIAK) merupakan suatu sistem informasi yang dirancang dan dibuat berdasarkan prosedur serta aturan pelayanan administrasi kependudukan yang menerapkan sistem teknologi informasi komunikasi berguna untuk menata sistem administrasi kependudukan di Indonesia. Sistem informasi ini bertujuan untuk pencatatan administrasi sipil diantaranya untuk memenuhi hak asasi setiap orang di bidang Administrasi Kependudukan tanpa diskriminasi dengan pelayanan publik yang profesional, meningkatkan kesadaran Penduduk akan kewajibannya untuk berperan serta dalam pelaksanaan Administrasi Kependudukan, mendukung 
perumusan kebijakan dan perencanaan pembangunan secara nasional, regional, serta lokal, hingga berguba untuk mendukung pembangunan sistem Administrasi Kependudukan.

Sistem tersebut difungsikan untuk melakukan pendaftaran penduduk yang meliputi pencatatan biodata penduduk, pencatatan akan pelaporan peristiwa diantaranya penerbitan KK, perubahan alamat, pendaftaran penduduk pndah datang alam wilayah dan antarnegara, pendaftaran penduduk pelintas batas dan pendaftaran penduduk rentan. Pencatatan sipil meliputi kelahiran, lahir mati, perkawinan, pembatalan perkawinan, perceraian, pembatalan perceraian, kematian dan pengangkatan, pengakuan hingga pengesahan anak. Pendataan dari sistem itu dapat digunakan sebagai dokumen atau pendaatan dari bagian selain pencatatan sipil, data ini dapat diintegrasikan langsung melalui sistem informasi tersebut, akun yang dimiliki oleh pegawai pecatatan sipil tidak dapat digunakan orang lain tanpa persetujuan dari pihak terkait, dengan ini data dapat diakses melalui sistem tetapi dengan batasan tertentu yang telah ditentutan seperti hanya bisa melakukan pengaksesan data anak untuk bagian pendataan anak[13].

Hardskill adalah kemampuan yang dimiliki oleh sesorang dan dapat diasah dan digali melalui pelatihan maupun praktek kerja lapangan untuk bekal kemampuan di dunia kerja. Hardskill yang harus dimiliki oleh pegawai kantor dinas kependudukan dan pencatatan sipil kabupaten Sleman yakni kemampuan untuk mengoperasikan komputer juga mampu menjalankan sistem informasi dengan baik agar dapat mengelola, memodifikasi dan mempelajari sistem yang digunakan diberbagai bidang. Tidak hanya memiliki kemampuan dalam pengoperasian komputer serta sistem, diperlukan juga kemampuan bersosialisasi dan cepat tanggap terhadap masyarakat[14]. Menangani laporan dan keluhan masyarakat terkait pencatatan kependudukan membuat para karyawan harus mampu memberikan respon yang kompetibel terhadap masyarakat, agar terjadi singkronasi terhadap hardskill dan softskill.

Softskill adalah suatu kemampuan seseorang dalam komunikasi, karakteristik, sifat, interaksi terhadap sosial yang melekat, hingga kemampuan adaptasi terhadap lingkungan sekitar meliputi rekan kerja dalam kehidupan maupun dunia kerja, softskill yang diperlukan di kantor kependudukan dan pencatatan sipil kabupaten Sleman yakni team work, manajemen waktu, hingga kepribadian yang baik, dibuktikan dengan semua karyawan diwajibkan untuk datang tepat waktu dan pulang tepat waktu kemudian diperlukan komunikasi yang baik antar sesama[15]. Kerjasama juga diperlukan untuk menunjang berjalannya semua kegiatan yang ada, kerjasama ini dijalankan mulai dari sub bidang, bidang hingga semua pegawai yang bekerja. Rasa tanggung jawab terhadap tugas yang diberikan juga tak kalah penting diperhatikan, pada dasarnya kantor kependudukan dan pencatatan sipil tempat untuk melakukan administrasi kependudukan sehingga masyarakat akan silih berganti dan tak hentinya harus dilayani dan dilakukan pencatatan dan perubahan data. Sehingga data atau pekerjaan setiap pegawai harus diselesaikan tepat waktu.

\section{KESIMPULAN}

Kantor Kependudukan dan Pencatatan Sipil Kabupaten Sleman merupakan salah satu kantor lembaga pemerintahan yang bertujuan untuk menyelenggarakan dan penataan struktur data pencatatan kependudukan. Berguna untuk melakukan pendataan tentunya memerlukan sebuah sistem yang nantinya menghasilakan sebuah database dan untuk memudahkan segala urusan mengenai pendataan. Pengelolaan data tersebut, pegawai dapat memperoleh kemudahan dalam mencari informasi, menyimpan informasi dan membuang informasi. Kantor DUKCAPIL Kabupaten Sleman terdapat beberapa Bidang dan Bagian, sistem yang digunakan pada Bagian Arsip disebut dengan SIMARDA (Sistem Manajemen Arsip Daerah), sistem pada Bagian Keuangan bernama SIADINDA (Sistem Administrasi Daerah) dan bagian pendaftaran Penduduk menggunakan SIAK (Sistem Informasi Administrasi Kependudukan).Sistem yang diterapkan sebelum adanya sistem dirasa tidak efektif dan efiien yang dapat dirasakan secara waktu data yang ditulis secara manual membuat pengintegrasian data menjadi lebih sulit karena bentuk fisik adalah kertas. Selain kegiatan menjadi lama dan lambat dokumen harus disalin untuk disebarkan keseluruh bagian sebagai bahan acuan data sehingga penggunaan kertas sangat melimpah dan banyak.

Penerapan teknologi informasi guna menunjang proses administrasi pendataan sudah dilakukan secara terintegrasi, dibuktikan dengan adanya beberapa sistem informasi yag berguna untuk pendataan, pengelolaan, dan sumber informasi mengenai data penduduk yang ada di Kabupaten Sleman. Faktor yang mempengaruhi implementasi kebijakan yang meliputi komunikasi, sumber daya dan disposisi berjalan dengan efektif. Ditinjau dari adanya komunikasi yang terjalin baik, pelatihan dan bimbingan mengenai teknologi sumber daya dan sikap loyal pegawai terhadap kebijakan. Pengelolaan dan penggunaan sistem informasi administrasi kependudukan (SIAK) sudah cukup baik. Sayangnya terkait hal kecepatan dan ketepatan waktu pendaftaran penduduk belum berjalan dengan optimal karena beberapa faktor, termasuk kurangnya pegawai. Konteks pencatatan sipil sudah berjalan dengan baik dilihat dari kerja pegawai selalu berlandaskan dengan kesepakatan dan aturan yang berlaku, konteks pengelolaan informasi juga sudah cukup baik dapat dilihat dari pemanfaatan teknologi yang ada. Hal yang dapat meningkatkan pengelolaan informasi salah satunya sumber daya manusia yang harus ditambah guna meningkatkan kecepatan dan efektifitas pelayananan di kantor dinas kependudukan dan pencatatan sipil kabupaten sleman. Sarana dan prasarana penunjang dalam pelayanan, pendataan, pengelolaan hingga penyimpanan data kependudukan sudah lengkap untuk kelancaran pelayanan. 


\section{REFERENSI}

[1] L. Tarifu, "Implementasi Sistem Informasi Administrasi Kependudukan Dalam Pelayanan Kartu Tanda Penduduk Pada Dinas Kependudukan Dan Catatan Sipil Kota Kendari,” J. Publicuho, vol. 3, no. 2, p. 233, 2020, doi: 10.35817/jpu.v3i2.12511.

[2] K. Anam, "Analisa Dan Perancangan Sistem Informasi Akademik Berbasis Web Pada Mi Al-Mursyidiyyah Al-‘Asyirotussyafi'Iyyah,” J. Tek. Inform., vol. 11, no. 2, pp. 207-217, 2018, doi: 10.15408/jti.v11i2.8867.

[3] M. A. Lestari, M. Tabrani, S. Ayumida, P. Data, A. Kependudukan, and K. Desa, "SISTEM INFORMASI PENGOLAHAN DATA ADMINISTRASI KEPENDUDUKAN PADA KANTOR DESA PUCUNG KARAWANG," vol. 13, no. 3, pp. 14-21.

[4] Suryati. bambang eka purnama, "Pembangunan Sistem Informasi Pendataan Rakyat Miskin Untuk," J. Speed 13, vol. 9, no. 2, pp. 72-81, 2012.

[5] B. A. B. Ii, “3 421 ," no. 24, pp. 10-36, 2007.

[6] A. Anisah and M. S. Mayasari, "Desain Database Sistem Informasi Penerimaan Peserta Didik Baru Pada Selective English Course," Simetris J. Tek. Mesin, Elektro dan Ilmu Komput., vol. 7, no. 1, p. 183, 2016, doi: 10.24176/simet.v7i1.503.

[7] M. Alda, "Sistem Informasi Pengolahan Data Kependudukan Pada Kantor Desa Sampean Berbasis Android," vol. 4, pp. 1-8, 2020, doi: 10.30865/mib.v4i1.1716.

[8] J. I. Vol, “JURNAL INFORMATIKA Vol. 8, No. 1, Januari 2014,” vol. 8, no. 1, pp. 858-869, 2014.

[9] D. Susilowati, "Sistem Informasi Administrasi Kependudukan Berbasis Web Desa Sawahan," vol. 3, no. 2, pp. 77-81, 2017.

[10] I. G. I. Sudipa and E. A. P. Lestari, "Rancang Bangun Sistem Informasi Penduduk Dusun (Studi Kasus : Dusun Tegal Kori Kaja Ubung)," J. Teknol. Inf. dan Komput., vol. 5, no. 2, 2019, doi: 10.36002/jutik.v5i2.782.

[11] Santoso. 2008. Administrasi Publik Teori dan Aplikasi Good Governance, PT Refika Aditama:Bandung. Soemato, Triyuni dan Hendrastuti.2011. Administrasi Kependudukan Berbasis Registrasi. Bandung : Yayan Bina Profesi Mandiri

[12] Sugiyono. 2004. Metode Penelitian Administratif, Rineka Cipta:Jakarta. Sujarweni. 2014. Metode Penelitian Lengkap, Praktis dan Mudah Dipahami, Pustaka Baru Press:Yogyakarta.

[13] Sutabri, Tata. 2005. Sistem Informasi Manajemen. Andi Offset. Yogyakarta. Sutanta, Edy. 2003. Sistem Basis Manajemen. Jakarta :Graha Ilmu.

[14] A.M. Masalah, Nilai Pelayanan Publik, no. 2000.

[15] Manara, "Hard Skills Dan Soft Skills Pada Bagian Sumber Daya Manusia Di Organisasi Industri," J. Psikol. Tabularasa, vol. 9, no. 1, pp. 37-47, 2014. 